\title{
Optical and electrical characterization of $\mathrm{Bi}_{\mathrm{x}} \mathrm{Se}_{1-\mathrm{x}}$ thin films
}

\author{
M. M. Ibrahim, S. A. FAYeK, G.A.M. Amin*, D.M. Elnagar \\ NCRRT, P.O. Box 8029-Nasr City, Cairo, Egypt
}

\begin{abstract}
Bulk samples of the $\mathrm{Bi}_{\mathrm{x}} \mathrm{Se}_{1-\mathrm{x}}$ system with $(\mathrm{x}=0,5$, and 10) were prepared using conventional melt quenching technique. Thin films were then deposited by thermal evaporation technique under high vacuum conditions from the prepared bulk samples. Effect of Bi substitution on surface morphology, electrical and optical properties of $\mathrm{Bi}_{\mathrm{x}} \mathrm{Se}_{1-\mathrm{x}}$ thin films was studied. X-ray diffraction studies showed the formation of nanocrystalline clusters at Bi concentration $\mathrm{x}=10$. Formation of these clusters resulted in a rough surface which was confirmed by AFM measurements. The film surface was smooth, with RMS roughness of $0.0124 \mathrm{~nm}$ for $\mathrm{Bi}_{5} \mathrm{Se}_{95}$. For $\mathrm{Bi}_{10} \mathrm{Se}_{90}$, the RMS roughness increased to $3.93 \mathrm{~nm}$ indicating the formation of $\mathrm{Bi}_{2} \mathrm{Se}_{3}$ clusters. A simple hot probe technique showed a transition from p-type to n-type due to Bi incorporation. Charge transport mechanisms were investigated by temperature dependent DC electrical conductivity measurements in the temperature range of $209 \mathrm{~K}$ to $313 \mathrm{~K}$. Electrical activation energy $(\Delta \mathrm{E})$ of the films with different Bi concentrations was found to exhibit a notable change at the $\mathrm{p}$ to $\mathrm{n}$ transition. At low temperature, the conduction was in reasonable agreement with Mott's condition of variable range hopping. Mott parameters and the density of localized states near Fermi level were evaluated and correlated with the structural changes resulting from $\mathrm{Bi}$ addition. In addition, a red shift of the optical absorption edge of the films under study caused by $\mathrm{Bi}-\mathrm{Se}$ substitution was observed. Slight changes in the optical parameters were observed with the $\gamma$-irradiation. Addition of $\mathrm{Bi}$ atoms could be used to tailor the structural, electrical and optical properties of chalcogenide materials such as junctionless photovoltaic devices.
\end{abstract}

Keywords: chalcogenides; electrical conductivity; optical properties; $\gamma$-radiation

(C) Wroclaw University of Technology.

\section{Introduction}

Chalcogenide glasses are a special type of amorphous semiconducting materials which have some unique properties that play a vital role in the field of infrared optics, memory devices, fiber optics, optoelectronics, lithography, xerography, etc. $[1,2]$. Chalcogenide glasses that have relatively low connectivity, well below an average coordinate number of 2.4 [3] are termed floppy or under-coordinated glasses. Such glasses could be a chalcogen-rich composition, like the glass containing $90 \%$ Se. These glasses generally exhibit excessive built-in stress and can relatively easily undergo a transition to a phase separated material that is at least partially crystallized. Amorphous selenium as a chalcogenide material became a material of commercial importance. Its various device applications, such as rectifiers, photocells, xerographs, switching and memory devices, etc. have made it attractive.

*E-mail: gamalamin@yahoo.com
However, pure selenium has disadvantages, such as short lifetime and low photosensitivity. This problem can be overcome by the incorporation of group III, IV, V, and VI elements [4]. Chalcogenide glasses invariably display p-type electronic conductivity, and are known to remain p-type when melted with common donor atoms. $\mathrm{Pb}$ or Bi doped chalcogenide are the only melt doped chalcogenide glasses in which carrier-type reversal [CTR] has been observed [5]. Therefore $\mathrm{Bi}$ was added to $\mathrm{Se}$ for studying the phenomenon which is related to the chemistry of the system and has an effect on its optical and electrical parameters. Because of the anomalous behavior of $\mathrm{Bi}$ when included in larger quantity, two different concentrations of $\mathrm{Bi}$ were studied. On the other hand, introducing $\mathrm{Bi}$ atoms into a matrix rich of chalcogen atoms enables the study of formation of tiny crystals in chalcogenide glass films as a material for nano-dipole junctionless photovoltaic devices [6]. Also, the effect of $\gamma$-radiation on some parameters in correlation with composition was studied. 


\section{Experimental}

Bulk glassy $\mathrm{Bi}_{\mathrm{x}} \mathrm{Se}_{1-\mathrm{x}}$ alloys with $\mathrm{x}=(0,5$ and 10) were prepared from high purity, $(5 \mathrm{~N})$, Se and $\mathrm{Bi}$ by the well-known melt quenching technique. The successful method for obtaining thin films with homogenous composition and thickness from the melt quenched ingot was the thermal evaporation technique under vacuum of $1 \times 10^{-4} \mathrm{~Pa}$, with the substrate heated to about $150{ }^{\circ} \mathrm{C}$. The film thickness was monitored during the deposition process using a quartz crystal thickness monitor (Edward FTM5), and it was in the range of $1800 \AA$ to $2000 \AA$. Elemental analysis of the prepared films was performed using energy dispersive X-ray, EDX spectrometer attached to a Joel JSM-5410 scanning electron microscope. EDX analysis results were obtained for three randomly selected areas to confirm compositional homogeneity (Table 1). Structure of thin films was evaluated by a Shimadzu $\mathrm{X}$-ray diffractometer, model XD-D1 with $\mathrm{CuK} \alpha$ radiation target, $\lambda=1.5418 \AA$, operated at $40 \mathrm{kV}$ and $30 \mathrm{~mA}$ in a wide range of Bragg's angles $\left(2 \theta=5^{\circ}\right.$ to $\left.90^{\circ}\right)$. Film morphology was studied using an atomic force microscope, AFM, Agilent type, AFM 5500, USA. AFM is a powerful tool to obtain high resolution maps of surface potential distribution on conducting and non-conducting samples. Contact potential difference better than $0.1 \mathrm{mV}$ and the lateral dimension $(\leqslant 50 \mathrm{~nm})$ were obtained for the samples under investigation. A conventional hot-probe experiment was used to distinguish between n-type and p-type semiconductors using a hot probe and a standard multimeter. Positive voltage read out was obtained for n-type semiconductor whereas for a p-type semiconductor, negative voltage was measured. Thin film samples were deposited on glass substrates in a co-plannar configuration, with Au electrode separated by $\sim 0.15 \mathrm{~cm}$ gap for DC conductivity measurements. The measurements were carried out under controlled equilibrium conditions in the temperature range of $209 \mathrm{~K}$ to $313 \mathrm{~K}$ (glass transition temperature $\mathrm{T}_{\mathrm{g}} \sim 326 \mathrm{~K}$ ). Keithly 617 digital electrometer as well as a power supply and temperature controller were used in a special setup for conductivity measurements. Optical absorption was recorded using a double-beam Shimadzu 160A UV-Vis spectrophotometer in the wavelength range of $200 \mathrm{~nm}$ to $1100 \mathrm{~nm}$, with normal incidence at room temperature. Effect of $\gamma$-irradiation was studied for the films of a thickness of $400 \mathrm{~nm}$ with the doses up to $51 \mathrm{kGy}$ in a $\mathrm{Co}^{60}$ source of $\gamma$-radiation type $400 \mathrm{~A}$ (India) at a dose rate of $5 \mathrm{kGy} / \mathrm{h}$.

\section{Results and discussion}

\subsection{Structural properties}

Structure and surface morphology of $\mathrm{Bi}_{\mathrm{x}} \mathrm{Se}_{1-\mathrm{x}}$ thin films were studied by X-ray diffraction XRD and atomic force microscopy. XRD patterns in Fig. 1 show the amorphous nature of Se, but due to addition of $\mathrm{Bi}$ there is a diffraction peak at $2 \theta=23.49^{\circ}$ for $\mathrm{Bi}_{5} \mathrm{Se}_{95}$ and at $2 \theta=23.48^{\circ}$ for $\mathrm{Bi}_{10} \mathrm{Se}_{90}$. There is also a small diffraction peak at $2 \theta=29.26^{\circ}$ for $\mathrm{Bi}_{10} \mathrm{Se}_{90}$ film due to some crystal features of the film. By fitting the relative intensities and the peak positions in the XRD patterns, it was found that the diffraction peak at $2 \theta=23.48^{\circ}$ is due to Bi atoms (PDF card file No. 69-901-1997) and the peak at $2 \theta=29.26^{\circ}$ for the $\mathrm{Bi}_{10} \mathrm{Se}_{90}$ film is due to the presence of $\mathrm{Bi}_{2} \mathrm{Se}_{3}$ clusters (PDF card file No. 69-901-1966). Formation of these clusters resulted in a rough surface which was confirmed by AFM measurements as shown in Fig. 2. The film surface of $\mathrm{Bi}_{5} \mathrm{Se}_{95}$ is smooth with RMS roughness of $0.0124 \mathrm{~nm}$ but for $\mathrm{Bi}_{10} \mathrm{Se}_{90}$ the RMS roughness increased to about $3.93 \mathrm{~nm}$ confirming the formation of $\mathrm{Bi}_{2} \mathrm{Se}_{3}$ clusters which show strong n-type conduction [7].

\subsection{Electrical properties}

Measurement results of DC conductivity as a function of temperature in the range between $209 \mathrm{~K}$ and $313 \mathrm{~K}$ (Fig. 3) were used for examination of conduction mechanisms in $\mathrm{Se}, \mathrm{Bi}_{5} \mathrm{Se}_{95}$, and $\mathrm{Bi}_{10} \mathrm{Se}_{90}$. Temperature dependence of the DC conductivity can be explained by the conventional relation [8]:

$$
\sigma_{d c}=\sigma_{0} \exp \left(-\Delta E_{\sigma} / k T\right)+\sigma_{1} \exp \left(-\Delta E_{1} / k T\right)
$$

The first term describes high temperature region, where the dominant mechanism is the band 
Table 1. EDX data for $\mathrm{Bi}_{\mathrm{x}} \mathrm{Se}_{1-\mathrm{x}}$ system.

\begin{tabular}{ccccc}
\hline Composition & Bulk & \multicolumn{3}{c}{ Thin film } \\
\hline \hline & Se [at.\%] & Bi [at.\%] & Se [at.\%] & Bi [at.\%] \\
$\mathrm{Bi}_{5} \mathrm{Se}_{95}$ & 94.96 & 5.04 & 94.79 & 5.21 \\
$\mathrm{Bi}_{10} \mathrm{Se}_{90}$ & 90.39 & 9.61 & 90.03 & 9.97 \\
\hline
\end{tabular}

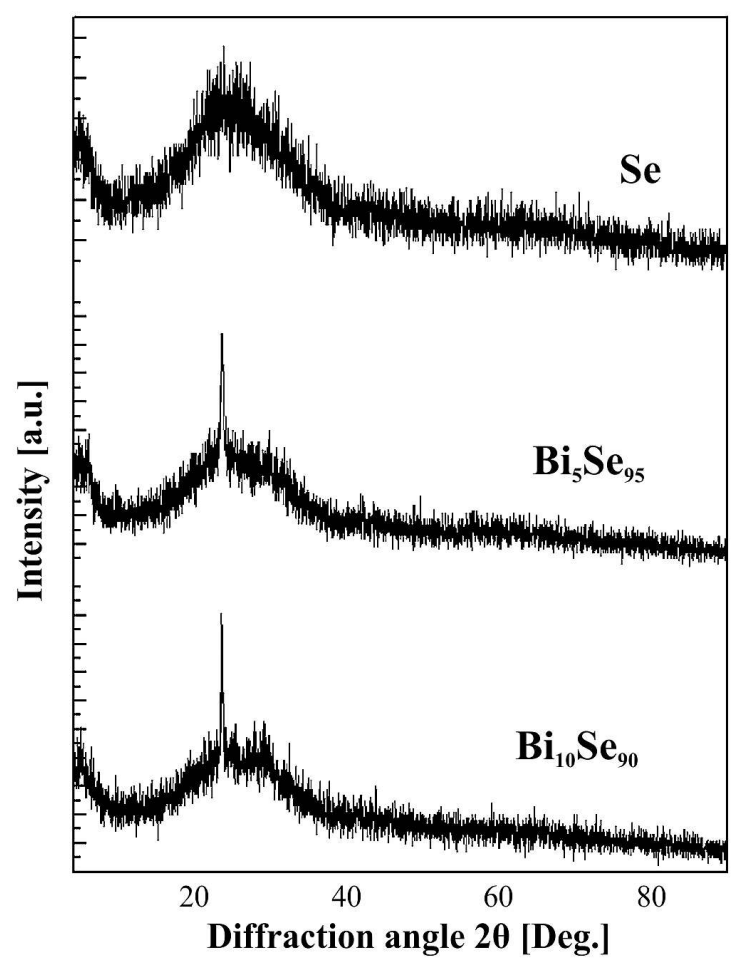

Fig. 1. XRD patterns of $\mathrm{Se}, \mathrm{Bi}_{5} \mathrm{Se}_{95}$ and $\mathrm{Bi}_{10} \mathrm{Se}_{90}$ thin films.

conduction through the extended states. The preexponential factor $\left(\sigma_{0}\right)$ depends on composition, $\Delta \mathrm{E}_{\sigma}$ is the electrical activation energy of conduction, $\mathrm{k}$ is the Boltzmann constant and $\mathrm{T}$ is temperature in Kelvin. Fig. 3 shows that the conductivity of the films increases with temperature, indicating the semiconducting behavior of the samples. Also the system follows the conduction mechanisms according to Mott's model for amorphous composition [9]. The values of activation energy were determined from the slopes of linear-least square fit of the plots of $\log (\sigma)$ versus 1000/T (region 1) using equation 1 . The values of activation energies are given in Table 2. There is a remarkable change

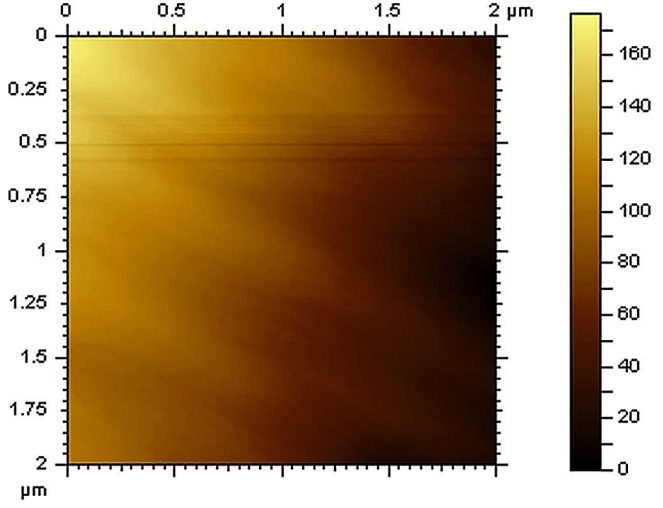

(a)

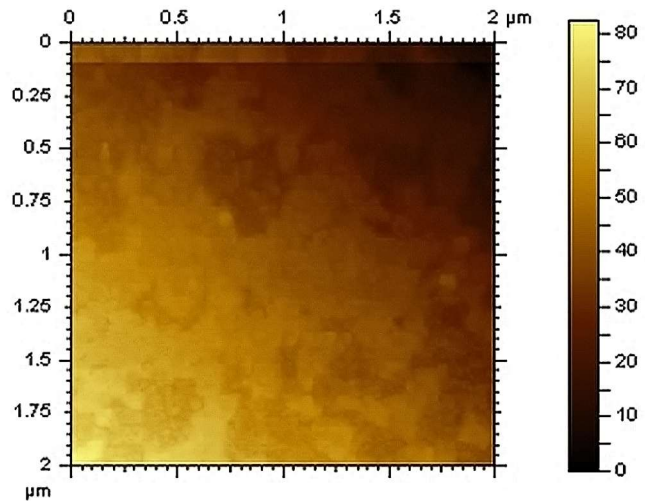

(b)

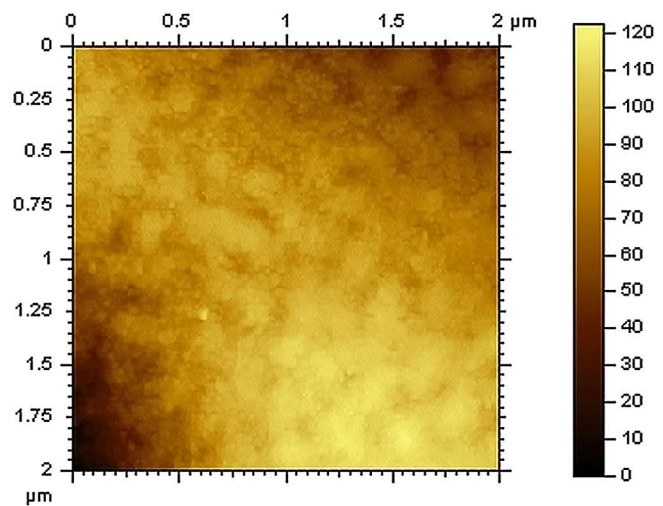

(c)

Fig. 2. AFM images of $\mathrm{Se}, \mathrm{Bi}_{5} \mathrm{Se}_{95}$ and $\mathrm{Bi}_{10} \mathrm{Se}_{90}$ thin films. 
in the activation energies $\left(\Delta \mathrm{E}_{\sigma}\right)$ and $\left(\Delta \mathrm{E}_{1}\right)$ with increasing Bi content. This could be attributed to the change of conduction type, (CTR), from p-type for Se to n-type for $\mathrm{Bi}_{5} \mathrm{Se}_{95}$ and $\mathrm{Bi}_{10} \mathrm{Se}_{90}$. This phenomenon can be explained in terms of unpinning of the Fermi level and the consequent enhancement in electron concentration in the medium. According to [7], the n-type conduction in $\mathrm{Bi}_{10} \mathrm{Se}_{90}$ composition is due to the formation of $\mathrm{Bi}_{2} \mathrm{Se}_{3}$ crystalline clusters which are uniformly distributed in the glass matrix as shown in AFM image, Fig. 2. The sharp decrease of $\Delta \mathrm{E}$ of $\mathrm{Bi}_{5} \mathrm{Se}_{95}$ composition may be due to a change in bonding type, from covalent to partially ionic, at the $\mathrm{Bi}$ sites [10]. At low temperature region in Fig. 4, conduction occurs via variable range hopping of charge carriers in the localized states near Fermi level, and is characterized by Mott's variable range hopping VRH [11, 12]:

$$
\begin{gathered}
\sigma_{h}=\sigma_{h o} \exp \left[\left(-T_{o} / T\right)^{1 / 4}\right] \\
A^{4}=T_{0}=\left(\lambda \alpha^{3} / k N\left(E_{f}\right)\right.
\end{gathered}
$$

where $\mathrm{Df}_{\mathrm{h}_{\mathrm{o}}}$ is the pre-exponential factor, $\alpha$ describes the spatial extent of localized wave function, $T_{0}$ is the degree of disorder, $\lambda$ is a dimensionless constant, $\mathrm{k}$ is the Boltzmann constant and $\mathrm{N}\left(\mathrm{E}_{\mathrm{f}}\right)$ is the density of localized states at the Fermi level $\left(\mathrm{E}_{\mathrm{f}}\right)$. Value of $\mathrm{Df}_{\mathrm{h}_{\mathrm{o}}}$ obtained by various scientists [13-15] is given by:

$$
D f_{h_{o}}=3 e^{2} \gamma\left[N\left(E_{f}\right) /(8 \pi \alpha k T)\right]^{1 / 2}
$$

where e is the electron charge and $\gamma$ is the Debye frequency $\left(10^{13} \mathrm{~Hz}\right)$. Simultaneous solution of equation 3 and equation 4 yields:

$$
\begin{gathered}
\alpha=22.52 D f_{h_{o}} \mathrm{~A}^{2} \mathrm{~cm}^{-1} \\
N\left(E_{f}=2.12 \times 10^{9} D f_{h_{o}} \mathrm{~A}^{2} \mathrm{~cm}^{-3} \mathrm{eV}^{-1}\right.
\end{gathered}
$$

Linear fit of the data shown in Fig. 4 indicates that temperature dependence of the conductivity in this temperature range satisfies Mott's formula. Straight lines parameters were used to calculate

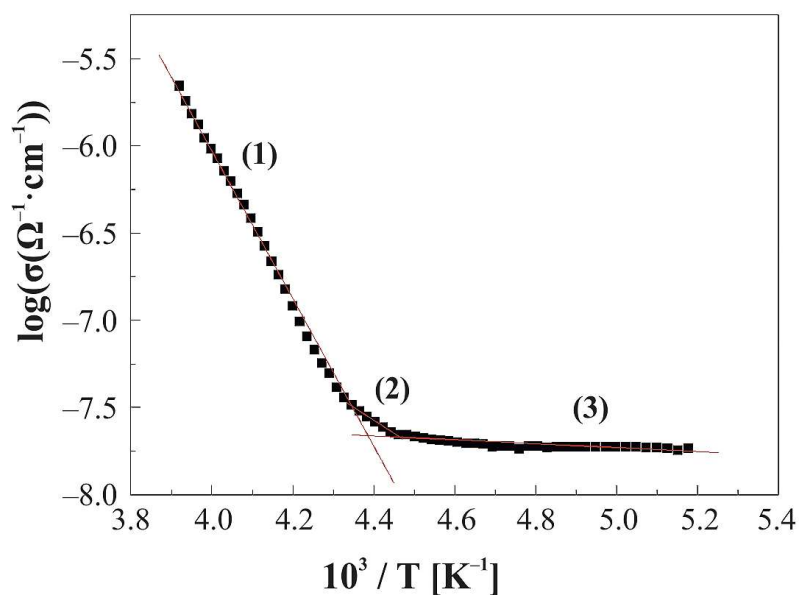

(a)

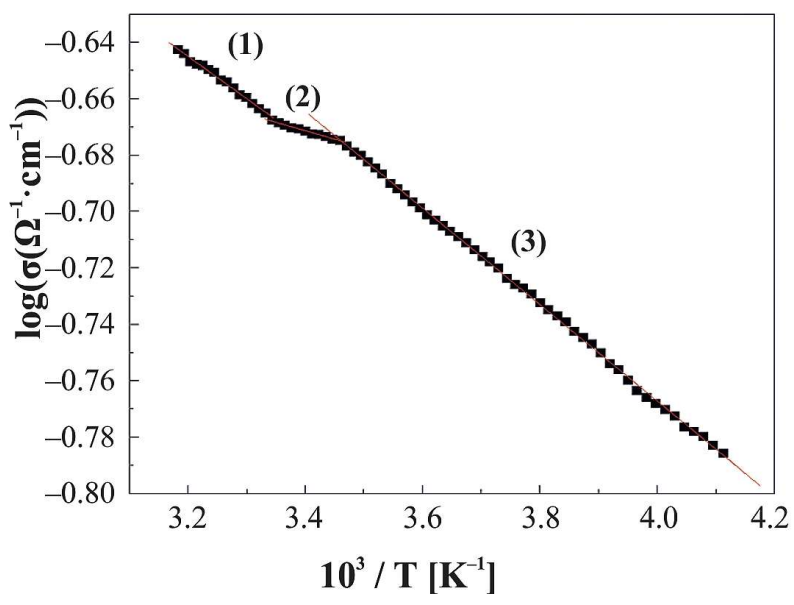

(b)

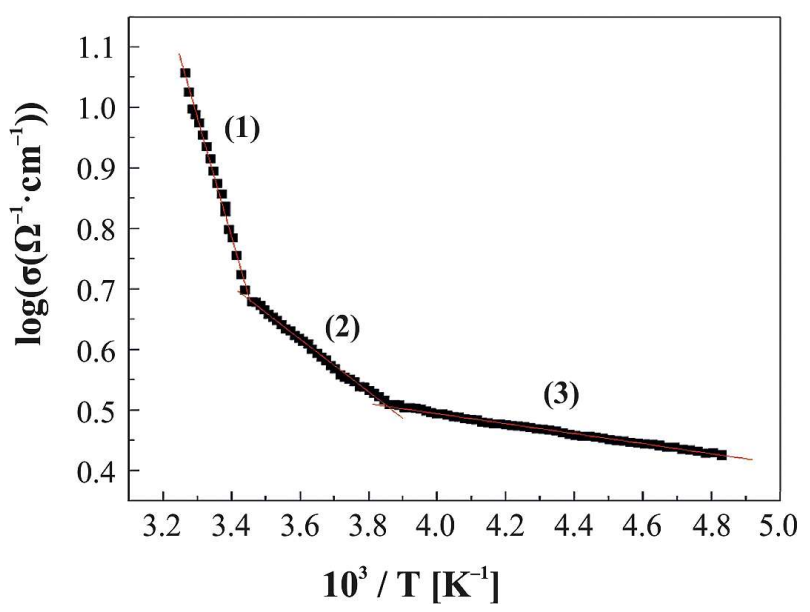

(c)

Fig. 3. Temperature dependence of DC conductivity of all studied films. 
Table 2. DC electrical parameters of $\mathrm{Bi}_{\mathrm{x}} \mathrm{Se}_{1-\mathrm{x}}$ system.

\begin{tabular}{ccccc}
\hline Composition & $\Delta \mathrm{E}_{\sigma}[\mathrm{eV}]$ & $\sigma_{o}[\Omega \cdot \mathrm{cm}]^{-1}$ & $\Delta \mathrm{E}_{1}[\mathrm{eV}]$ & $\sigma_{1}[\Omega \cdot \mathrm{cm}]^{-1}$ \\
\hline \hline $\mathrm{Se}$ & $0.99 \pm 0.12$ & $3.9 \times 10^{10}$ & $0.87 \pm 0.04$ & $3.3 \times 10^{11}$ \\
$\mathrm{Bi}_{5} \mathrm{Se}_{95}$ & $0.03 \pm 0.03$ & 0.69 & $0.12 \pm 0.002$ & $0.2 \times 10^{2}$ \\
$\mathrm{Bi}_{10} \mathrm{Se}_{90}$ & $0.14 \pm 0.02$ & $0.8 \times 10^{3}$ & $0.09 \pm 0.004$ & $0.15 \times 10^{3}$ \\
\hline
\end{tabular}

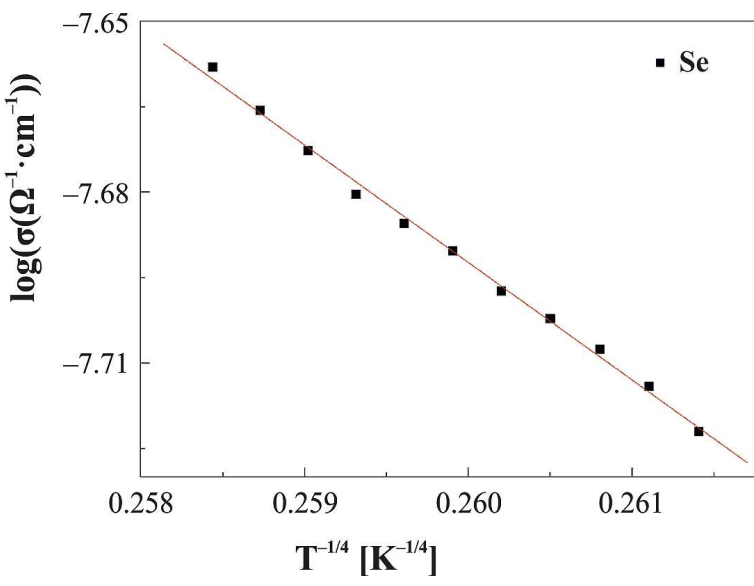

(a)

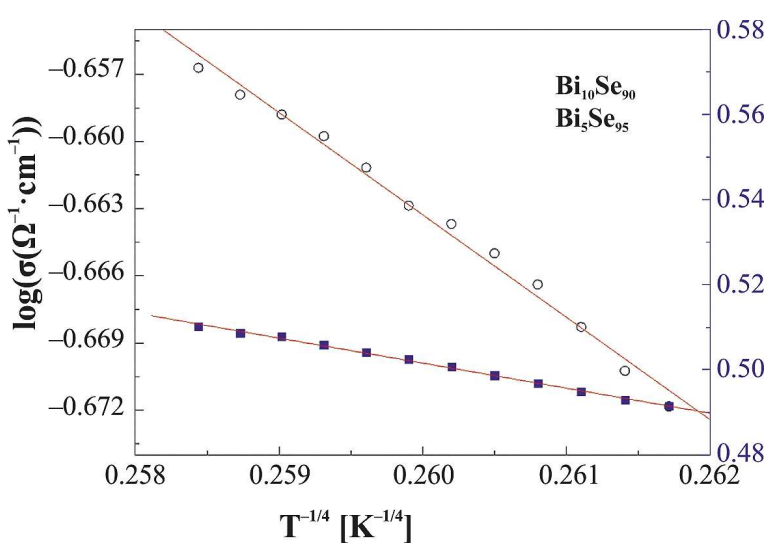

(b)

Fig. 4. $\log \left(\sigma\left(\Omega^{-1} \cdot \mathrm{cm}^{-1}\right)\right)$ vs. $\mathrm{T}^{-1 / 4}$ for all films indicating the variable range hopping conduction.

$\mathrm{N}\left(\mathrm{E}_{\mathrm{f}}\right)$ and consequently to calculate the basic parameters characterizing VRH conduction, namely the hopping distance $R_{h}$ is given by [15]:

$$
R_{h}=\left[\frac{9}{8 \pi \alpha N\left(E_{f}\right) k T}\right]^{1 / 4}
$$

while the hopping energy $\mathrm{W}$ is given by [15]:

$$
W=3 / 4 \pi R_{h}^{3} N\left(E_{f}\right)
$$

Compositional dependence of $\mathrm{A}, \sigma_{0}, \alpha, \mathrm{N}\left(\mathrm{E}_{\mathrm{f}}\right), \mathrm{T}_{0}$, $\mathrm{R}$ and $\mathrm{W}$ is given in Table 3. The results reveal that $\mathrm{T}_{\mathrm{o}}$, which represents the degree of disorder, decreases with increasing Bi content. This means that amorphicity of the samples decreases and there is some ordering as a result of formation of crystallites as confirmed by X-ray and AFM.

\subsection{Optical properties}

Analysis of optical absorption data is an important and efficient tool for exploring and interpreting various phenomena of electronic processes in materials subjected to ionizing radiation [16]. This also provides a strong tool for understanding the theory of electronic transport in all types of solid-state structures [17]. In various absorption processes, electrons and holes absorb both a photon which supplies the needed energy and a phonon which supplies the required momentum. The absorption coefficient $(\alpha)$ was calculated from the absorbance spectrum as expressed by:

$$
\alpha=2.303 A / t
$$

where $\mathrm{t}$ is the film thickness in $\mathrm{cm}$ and $\mathrm{A}$ is the absorbance given by:

$$
A=\log \left(I_{0} / I\right)
$$

where $I_{0}$ and $I$ are the intensity of incident and transmitted intensities respectively. The absorption edge at the calculated high values of absorption coefficient $\alpha \geqslant 10^{4} \mathrm{~cm}^{-1}$ can be described by the equation 11 :

$$
A h v=\beta\left(h v-E_{g}\right)^{n} / h v
$$

$\beta^{-1}$ is the band edge parameter and $n$ is an exponent which is a parameter associated with both transition type and profile of electron density in the 
Table 3. DC electrical parameters of $\mathrm{Bi}_{\mathrm{x}} \mathrm{Se}_{1-\mathrm{x}}$ system.

\begin{tabular}{ccccccccc}
\hline Composition & $\mathrm{A} \mathrm{K}^{1 / 4}$ & $\mathrm{~T}_{\mathrm{o}} \mathrm{K}$ & $\sigma_{\mathrm{ho}} \Omega^{-1} \cdot \mathrm{cm}^{-1}$ & $\alpha \mathrm{cm}^{-1}$ & $\mathrm{~N}\left(\mathrm{E}_{\mathrm{f}}\right) \mathrm{eV}^{-1} \cdot \mathrm{cm}^{-3}$ & $\mathrm{R}_{\mathrm{h}} \mathrm{cm}$ & $\mathrm{W} \mathrm{meV}$ & $\alpha \mathrm{R}$ \\
\hline \hline $\mathrm{Se}$ & 20.65 & $1.8 \times 10^{5}$ & $2 \times 10^{2}$ & $2 \times 10^{6}$ & $1.021 \times 10^{21}$ & $3 \times 10^{7}$ & 8 & $8.8 \times 10^{2}$ \\
$\mathrm{Bi}_{5} \mathrm{Se}_{95}$ & 7.21 & $2.7 \times 10^{3}$ & $0.1 \times 10^{2}$ & $1.4 \times 10^{4}$ & $6.87 \times 10^{22}$ & $3.6 \times 10^{-7}$ & 0.075 & 0.6 \\
$\mathrm{Bi}_{10} \mathrm{Se}_{90}$ & 5.61 & $9.9 \times 10^{2}$ & $8.1 \times 10$ & $5.7 \times 10^{4}$ & $1.87 \times 10^{23}$ & $2 \times 10^{-7}$ & 0.15 & 2.8 \\
\hline
\end{tabular}

valence and conduction bands. $\mathrm{E}_{\mathrm{g}}$ is the optical energy gap of the material. Plotting $(\alpha \mathrm{h} v)^{1 / n}$ versus $(\mathrm{h} v)$ and using an appropriate value of $\mathrm{n}$ to linearize the graph, we obtained $n$ values of $1 / 2$ or 2 for allowed direct or non-direct transitions, respectively. In the present case, the best fit was found for $\mathrm{n}=2$ to obtain $E_{g}$ as shown in Fig. 6. The values of $E_{g}$ are listed in Table 4. It is clear that there is no sharp absorption edge which is characteristic of glassy state. At low absorption region, the absorption coefficients $\alpha(v)$ near the band edge $\leqslant 10^{4} \mathrm{~cm}^{-1}$ show an exponential dependence on photon energy hv, which usually obeys Urbach's [18] empirical relation:

$$
\alpha(\omega)=\alpha_{0} \exp \left(h v / E_{e}\right)
$$

where $\alpha_{0}$ is a constant, $\omega$ is the angular frequency of incident photon, $h$ is the Planck's constant and $E_{e}$ is the width of band tail of localized states. The calculated values of the $\mathrm{E}_{\mathrm{e}}$ are listed in Table 4. It is clear that the steepness of the absorption edge is changing and a red shift in the absorption edge is observed due to introducing $\mathrm{Bi}$ atoms. According to [7], the red-shift is associated with the p-n transition or CTR. Also, addition of $\mathrm{Bi}$ to Se has an effect of increasing randomness and hence, a consequent increase in the localized states in the gap. Increasing the number of localized states in the gap increases the electronic transition probability leading to narrowing the band gap. Also, the red shift of the absorption edge could be related to the structural changes resulting from $\mathrm{Bi}$ addition [19]. The effect of $\gamma$-irradiation on optical absorption was studied for five irradiation doses up to $51 \mathrm{kGy}$. The results are tabulated in Table 4. Variation of absorption coefficient of Se thin film with the incident photon energy, for three $\gamma$-irradiation doses is shown in Fig. 7. It is clear that there is a shift in the absorption edge towards lower energies with irradiation dose. A similar pattern of change is observed for the samples doped with $\mathrm{Bi}$. It can be noticed that there is a slight change in $\mathrm{E}_{g}$ with increasing $\gamma$-doses. For $\mathrm{Bi}_{5} \mathrm{Se}_{95}$, shown in Fig. 8, this slight difference may be due to the creation of tiny defects in the sub-shell. Such results as in Table 4 indicate that the prepared films are almost stable against $\gamma$-irradiation and the CTR phenomenon is still in effect after $\gamma$-irradiation.

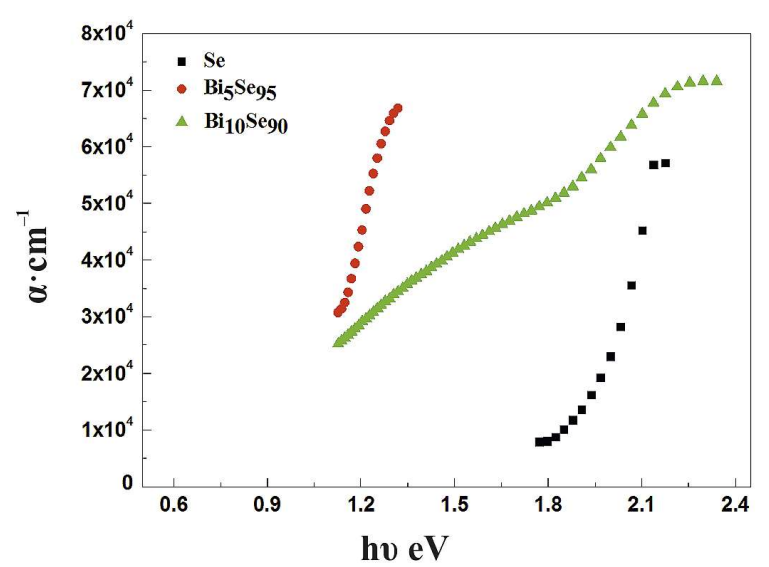

Fig. 5. Absorption spectra of all studied films.

Table 4. Values of optical parameters of $\mathrm{Bi}_{\mathrm{x}} \mathrm{Se}_{1-\mathrm{x}}$ system.

\begin{tabular}{crcc}
\hline Composition & \multicolumn{1}{c}{$\mathrm{E}_{\mathrm{T}} \mathrm{eV}$} & $\mathrm{E}_{\mathrm{e}} \mathrm{eV}$ & $\mathrm{B}_{1 / 2}(\mathrm{eV} \cdot \mathrm{cm})^{-1 / 2}$ \\
\hline \hline $\mathrm{Se}$ & $1.8 \pm 0.05$ & $0.2 \pm 0.01$ & 978.72 \\
$\mathrm{Bi}_{5} \mathrm{Se}_{95}$ & $0.87 \pm 0.05$ & $0.21 \pm 0.03$ & 655.27 \\
$\mathrm{Bi}_{10} \mathrm{Se}_{90}$ & $0.65 \pm 0.05$ & $0.52 \pm 0.03$ & 245.38 \\
\hline
\end{tabular}

\section{Conclusions}

In conclusion, addition of $\mathrm{Bi}$ atoms can be used to tailor the structural, electrical and optical properties of chalcogenide materials. 


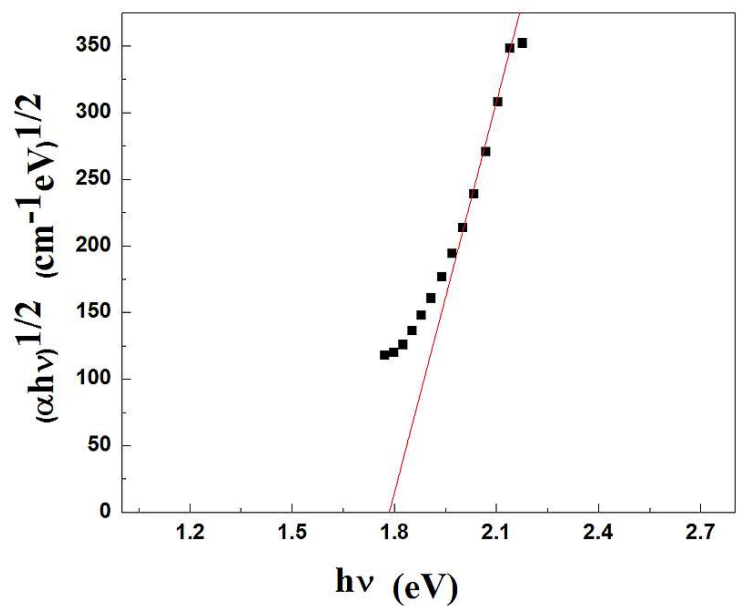

(a)

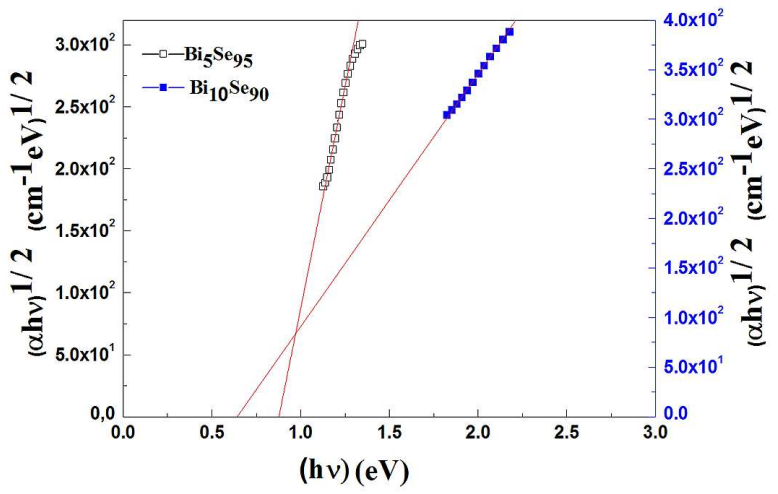

(b)

Fig. 6. Relation between $(\alpha \mathrm{h} v)^{1 / 2}$ and photon energy $\mathrm{h} v$ for all studied films.

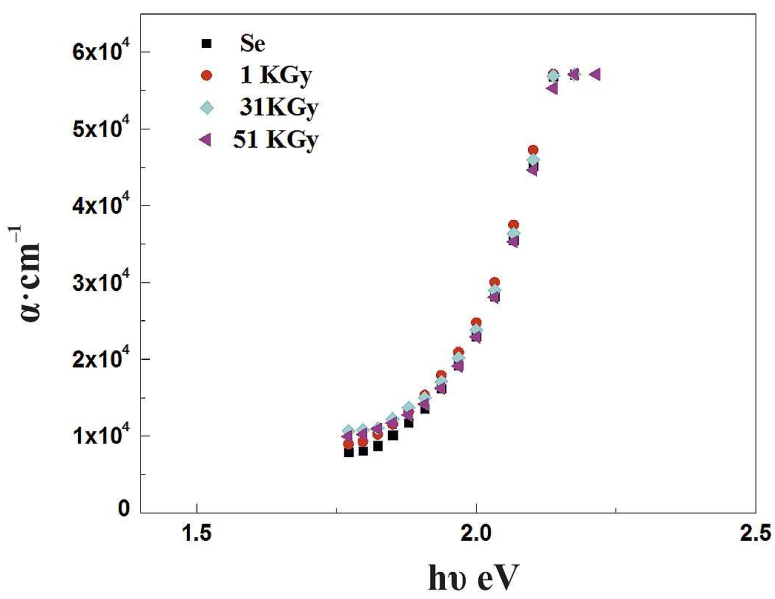

Fig. 7. Absorption spectra for as-deposited Se thin film and Se thin film $\gamma$-irradiated with different doses.

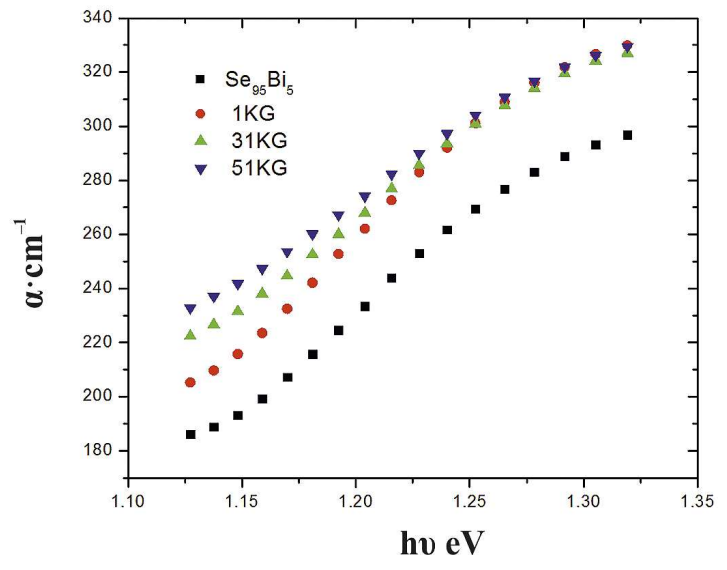

Fig. 8. Absorption spectra for as-deposited $\mathrm{Bi}_{5} \mathrm{Se}_{95}$ thin film and $\mathrm{Bi}_{5} \mathrm{Se}_{95}$ thin film $\gamma$-irradiated with different doses.

Increasing the $\mathrm{Bi}$ content leads to the occurrence of dispersed nanocrystalline clusters of $\mathrm{Bi}_{2} \mathrm{Se}_{3}$ in the glassy host material of Se. Formation of these clusters leads to the change of conduction type from p-type to n-type conduction. Also the decreasing value of $\mathrm{T}_{0}$ obtained from VRH mechanism of conduction at low temperature confirms the presence of crystalline clusters. Addition of $\mathrm{Bi}$ to $\mathrm{Se}$ leads to a decrease of the optical energy gap due to the increase of localized states created as a result of structural and electronic changes induced by $\mathrm{Bi}$ atoms. The red shift of the absorption edge is caused by adding Bi to Se matrix. So, by carefully tailoring the properties, this material is a promising candidate to be used in junctionless photovoltaic devices. The studied SeBi films are almost stable against $\gamma$-irradiation and the observed CTR phenomenon is still in effect after $\gamma$-irradiation.

\section{References}

[1] Naik R., Ganesan R., Thin Solid Films, 579 (2015), 95.

[2] Hassanien A.S., AKL A.A., J. Non-Cryst. Solids, 432 (2016), 471.

[3] Thorpe M.F., Jacobs D.J., Chubynsky M.V., Phillips J.C., J. Non-Cryst. Solids, 266 (2000), 859.

[4] Sharma P., Karyal S.C., Physica B, 403 (2008), 3667.

[5] Hughes A.M., Gwilliam M.R., Homewood K., Gholipour B., HewaK W.D., LeE T., Elliott S.R., Suzuki T., OHISHI Y., KOHOUTEK T., CURRY J.R., Opt. Express, 21 (7) (2013), 810. 
[6] Lu Y., Merrill J.M., Lusk M.T., Bailey S., Franceschetti A., Proc. MRS, (2001), 1322.

[7] Tichy L., Ticha H., Triska A., Nagles P., Solid State Commun., 53 (1985), 399.

[8] Motт N.F., DAvis E.A., Electronic Processes in NonCrystal Materials, $2^{\text {nd }}$ ed. Clarendon Press, Oxford, 1979.

[9] Davis E.A., Mотт N.F., Phil. Mag., 22 (1970), 903.

[10] Elliott S.R., Steel A.T., J. Phys. C-Solid State Phys., 20 (27) (1987), 4335.

[11] Pendry J.B., J. Phys. C-Solid State Phys., 20 (1987), 733.

[12] Hill R.M., Phys. Status Solidi A, 34 (2) (1976), 601.

[13] Twaddell V.A., Lacourse W.C. MacKenzie J.D., J. Non-Cryst. Solids, 8 - 10 (1972), 831.
[14] Touraine A., Vautier C., Carles D., Thin Solid Films, 9 (1972), 229.

[15] Swiler D.R., Varshncya A.K., Callahan R.M., J. Non-Cryst. Solids, 125 (1990), 250.

[16] Chopra K.L., Thin Film Phenomena, Malabar: Robert E. Krieger Publishing Company, 1979.

[17] Yamaguchi M., Phil. Mag. B, 5 (6) (1985), 61.

[18] Urbach F., Phys. Rev., 92 (1953), 1324.

[19] Al-Zahrani J.H., El-Hagary M., El-Taher A., Mat. Sci. Semicon. Proc., 39 (2015), 74.

Received 2015-12-21

Accepted 2016-03-10 